\title{
Kelimpahan Populasi dan Tingkat Parasitisasi Parasitoid Indigenus terhadap Hama Invasif Liriomyza trifolii (Burgess) (Diptera: Agromyzidae) pada Tanaman Asteraceae di Bali
}

\author{
I WAYAN SANDIKA YASA, I WAYAN SUPARTHA*), DAN \\ I WAYAN SUSILA
}

\author{
Program Studi Agroekoteknologi, Fakultas Pertanian, Universitas Udayana. \\ Jln. PB. Sudirman Denpasar Bali 80362 \\ ${ }^{*}$ E-mail: yansupartha@yahoo.com
}

\begin{abstract}
Population Abundance and Parasitization Level of Indigenous Parasites to Invasive Liriomyza trifolii (Burgess) (Diptera: Agromyzidae) on Asteraceae Plants in Bali. This study was aimed to determine the population abundance and parasitization level of indigenous parasitoid associated with Liriomyza trifolii (Burgess) in Asteraceae plants in Bali. The study was conducted from January to March 2019 by survey method on the type of parasitoid, abundance and parasitisation level in Asteraceae plants which included to Chrysanthemum, Gerbera jamesonii and Helianthus annuus, which are spread in several regencies in Bali such as Buleleng (1200 m asl), Bangli (900-1000 $\mathrm{m}$ asl) and Denpasar (40 m asl). Sampling was done purposively on the leaves of plants attacked by Liriomyza sp. and then maintained at the Laboratory until the parasitoid adults appeared. Afterward, morphologically was identified the type of parasitoid that appears. The results showed that there were three types of indigenous parasitoid associated with $L$. trifolii namely Hemiptarsenus varicornis, Neochrysocharis okazakii, and Opiusdissitus. The most dominant parasitoid of the three types of $\mathrm{H}$. varicornis parasitoid with an abundance of $78.57 \%$ and parasitization rate of $53.23 \%$ was found in Chrysanthemum plants.
\end{abstract}

Keywords: Asteraceae, Abundance, Parasitoid, Parasitization.

\section{PENDAHULUAN}

Asteraceae merupakan salah satu family tanaman yang banyak di manfaatkan di Indonesia. Menurut Cronguist (1981) tumbuhan suku A steraceae merupakan kelompok tumbuhan yang terdiri dari 1.100 marga yang meliputi 20.000 spesies. Beberapa jenis tanaman dari family Asteraceae yang dibudidayakan di Bali yaitu Chrysanthemum (Krisan), Gerbera jamesonii (Gerbera) dan Helianthus annuus (BungaMatahari). Dalam melakukan budidaya serangan hama dapat dapat menyebabkan penurunan kualitas dan kuantitas hasil, sehingga bermuara pada kerugian ekonomi yang dialami oleh petani. 
I WAYAN SANDIKA YASA. et al. Kelimpahan Populasi dan Tingkat Parasitisasi Parasitoid...

Salah satu jenis hama yang dapat menyerang tanaman A steraceae adalah Liriomyza.

Ada Sembilan spesies penambang daun yang telah tercatat di Indonesia, yaitu L. brassicae, L. caulophaga, L. chinensis, L. huidobrensis, L. katoi, L. pusila, L. sativae, L. chinensis, L. katoi, L. yasumatsui dan Chromatomyiahorticol (Malipatil dan Ridland 2008). Dua spesies yang telah ditemukan di Bali dan Lombok adalah L. huidobrensis dan L. sativae, yang masing- masing secara dominanter distribusi melalui dataran tinggi dan dataran rendah (Supartha 2003; Suparthaet al., 2005). Menurut Wahyuniet al., (2017) parasitoid yang berpotensi menjadi pengendali biologis terhadap Liriomyzaspp. di Kepulauan Sunda Kecil adalah Neochrisocarisformosa, $H$. varicornis dan Opius chromatomyiae. Upaya pengendalian LiriomyzaLiriomyza telah dilakukan di beberapa daerah di Indonesia dengan aplikasi insektisi dater jadwal, tetapi upaya tersebut belum dapat menekan populasi atau kerusakan yang terjadi pada tanaman (Baliadi 2009). Salah satu pengendalian yang efektif di lakukan untuk menekan perkembangan Liriomyzaspp.adalah dengan memanfaatkan musuh alaminya yaitu parasitoid.

Setidaknya 23 spesies parasitoid telah digunakan dalam program pengendalian biologis untuk $L$. trifolii Burgess dan $L$. sativae Blanchard (Diptera: Agromyzidae) di Senegal, California, Hawaii, Barbados, Marianas, Tonga, Taiwan dan Guam (Petcharat 2002). Beberapa peneliti di Indonesia telah menemukan sebanyak 17 spesies parasitoid yang memarasit Liriomyzaspp. (Raufet al., 2000; Ubaidillah 2003; Suparthaet al., 2005; Syamsudin 2008). Di antara parasitoid tersebut, $H$. varicornis telah ditemukan di adaptasikan ketanaman sayuran Indonesia (Baliadi dan Tengkano 2010) dan telah ditemukan mampu memparasitisasi $L$. huidobrensis pada tingkat 40,63\% (Setiawati danSuprihatno 2000).

Selama ini belum ada laporan tentang respon parasitoid indegenus terhadap Liriomyzatrifolii di Bali, sehingga penelitian ini bertujuan untuk mengetahui jenis, kelimpahan serta tingkat parasitisasi parasitoid yang berasosiasi dengan Liriomyzatrifolii pada tanaman A steraceae di Bali.

\section{METODE PENELITIAN}

Penelitian dilakukan di lapang dan laboratorium. Penelitian lapang dilakukan di daerah sentra tanaman A steraceae di Bali, yang meliputi Buleleng (1200 m dpl), Bangli (900-1000 m dpl) dan Denpasar (40 m dpl). 
Penelitian laboratorium dilaksankan di setiap unit sampel, akan dipakai 5 Laboratorium Pengelolaan Hama dan tanaman sebagai sampel dan setiap tanaman Penyakit Terpadu Tumbuhan, Fakultas sampel akan diambil 5 helai daun yang Pertanian, Universitas Udayana.

Penelitian ini dilakukan dengan metode survey kebeberapa tempat sentra tanaman A steraceae di Bali. Pengambilan sampel daun dilakukan dengan metode purposive terhadap daun tanaman yang teserang Liriomyzasp. Unit sampel ditentukan dengan metode diagonal sampling, dimana dalam menentukan tanaman sampel, digunakan metode purposive sesuai dengan gejala menunjukan gejala serangan Liriomyzasp.

Daun yang didapat dari lapang dikumpulkan dan diletakkan dalam wadahtransparan sehingga dapat dilihat serangga yang muncul (Supartha, 1998). Setelah imago parasitoid muncul selanjutnya di identifikasi meurut morfologinya dibawah microskopbinokular. Kelimpahan dan tingkat parasitisasi parasitoid dihitung dengan menggunakan rumus : serangan Liriomyzasp. yang tampak. Dalam

$$
\begin{aligned}
& \text { Kelimpahan }(\mathrm{K})=\frac{\text { Jumlah spesies yang ditemukan di lokasi }}{\text { Jumlah keseluruhan spesies yang terdapat di lokasi }} \times 100 \% \\
& P=\frac{\sum \text { imago parasitoid A }}{\sum \text { imago Liriomyza sp. }+\sum \text { imago parasitoid yang muncul }} \times 100 \%
\end{aligned}
$$

\section{Keterangan:}

$\mathrm{P}=$ tingkat parasitisasi (\%),

A = Jumlah imago salah satu parasitoid yang muncul,

Imago Liriomyzasp.= Jumlah total imago Liriomyzasp. yang muncul.

\section{HASIL DAN PEMBAHASAN}

Hasil penelitian menunjukkan terdapat tiga spesies parasitoid indegenus yang berasosiasi dengan Liriomyzatrifolii pada (Tabel 1). tanaman A steraceae di Bali, yang meliputi Hemiptarsenusvaricornis,

Neochrysocharisokazaki, dan Opiusdissitus 
I WAYAN SANDIKA YASA. et al. Kelimpahan Populasi dan Tingkat Parasitisasi Parasitoid...

Tabel 1.Jumlah dan jenis parsitoid pada beberapa tanaman A steraceae di Bali

\begin{tabular}{|c|c|c|c|c|c|c|}
\hline \multirow[b]{2}{*}{ Tanaman Inang } & \multirow[b]{2}{*}{$\begin{array}{c}\text { Lokasi } \\
\text { Penelitian }\end{array}$} & \multirow{2}{*}{$\begin{array}{c}\text { Jumlah Imago } \\
\text { Liriomyza } \\
\text { trifolii }\end{array}$} & \multicolumn{3}{|c|}{ Jenis Parasitoid } & \multirow[b]{2}{*}{ Jumlah } \\
\hline & & & $\begin{array}{l}\text { Hemiptarsenu } \\
\text { s varicornis }\end{array}$ & $\begin{array}{c}\text { Neochrysoca } \\
\text { ris okazaki }\end{array}$ & $\begin{array}{l}\text { Opius } \\
\text { dissitus }\end{array}$ & \\
\hline Chrysanthemum & $\begin{array}{l}\text { Pancasari, } \\
\text { Buleleng }\end{array}$ & 20 & 33 & 9 & - & 62 \\
\hline Helianthus aппииs & $\begin{array}{l}\text { Kebun } \\
\text { Percobaan } \\
\text { Fakultas } \\
\text { Pertanian, } \\
\text { Universitas } \\
\text { Udayana, } \\
\text { Denpasar } \\
\end{array}$ & 30 & - & 7 & 6 & 37 \\
\hline Gerbera jamesonii & $\begin{array}{l}\text { Pengotan, } \\
\text { Bangli }\end{array}$ & 2 & - & - & - & 2 \\
\hline
\end{tabular}

Terdapat tiga jenis parasitoid yang muncul dengan di dominasi oleh $H$. varicornis pada tanaman Krisan yang diambil dari Pancasari, Buleleng. Keragaman ini masih lebih rendah dibandingkan dengan parasitoid di habitat endemiknya, seperti di Peru, dimana lebih dari 20 jenis parasitoid dominan ditemukan (Cisneros \& Mujica, 2000).

Pada tanaman inang Helianthus annuus (Bunga Matahari) yang diambil dari Kebun Percobaan Fakultas Pertanian Universitas Udayana terdapat dua jenis parasitoid yang muncul yaitu $O$. disstiusdengan 6 imago dan N.okazakidengan 7 imago. Pada tanaman inang Chrysanthemum (Krisan) yang diambil di Desa Pancasari, Buleleng terdapat dua jenis parasitoid yang muncul yaituH. Varicornis dengan 33 imago dan $N$. Okazaki dengan 9 imago. Dari ketiga jenis parasitoid yang muncul $H$. varicornis menjadi parasitoid yang paling dominan dengan jumlah imago 33 ekor pada tanaman Chrysanthemum. Dominasi $H$. varicornis pada tanaman krisan diduga diakibatkan oleh tingginya jumlah inang yang ada di lapang, serta didukung oleh banyaknya sumber makanan yang berasal dari beberapa jenis gulma yang tumbuh. Hasil penelitian sebelumnya telah membuktikan bahwa berbagai jenis gulma dari keluarga Umbelliferae, Leguminosae, dan Compositae berperan penting sebagai sumber makanan bagi parasitoid dewasa untuk menekan populasi hama serangga (Altieri, 1999). 
AGROTROP, 10 (1): 59 - 66 (2020)

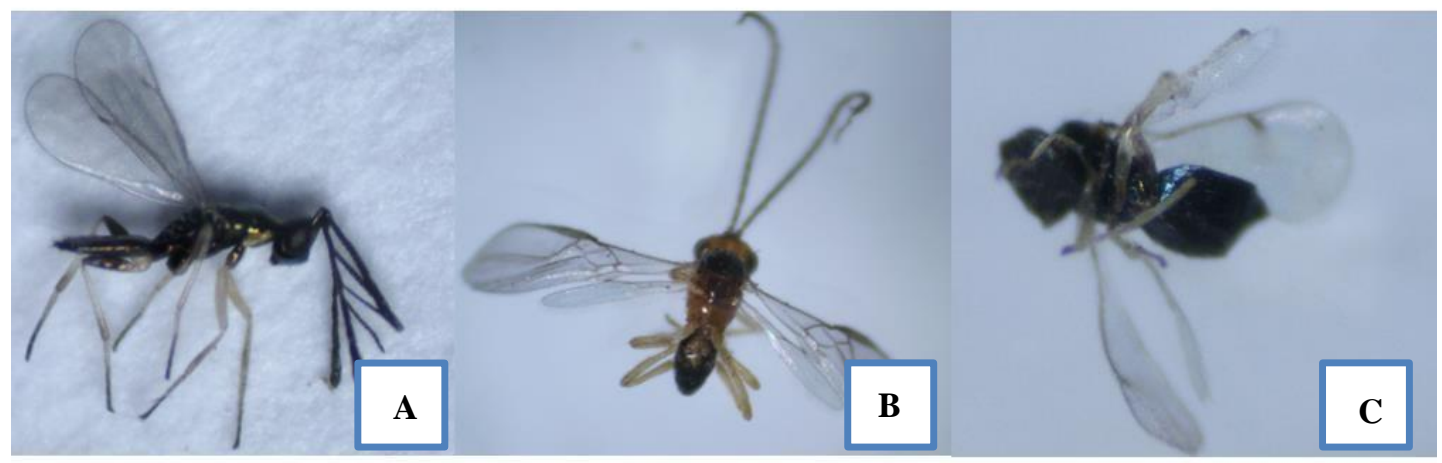

Gambar 1 Jenis parasitoid yang berasosiasi dengan Liriomyzatrifolii pada tanaman A steraceae di Bali dengan pembesaran 40x. (A) Hemiptarenusvaricornis ( $\overbrace{}^{\Uparrow}),(\mathrm{B})$ Opiusdissitus (ठ), dan (C) Neochrysocharisokazaki (ㅇ).

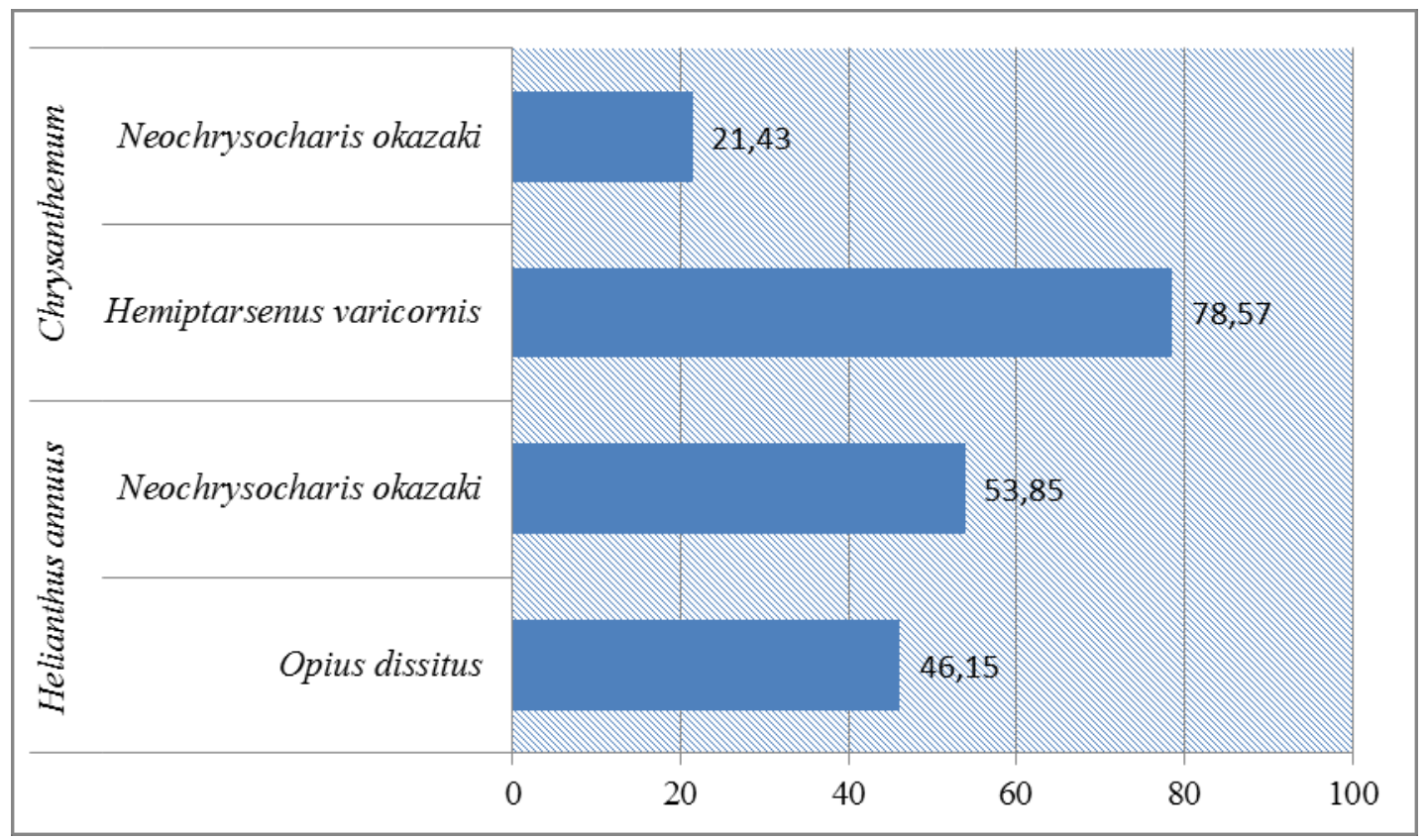

Gambar 2.Kelimpahan Parasitoid (\%) yang Berasosiasi dengan Liriomyzatrifoli . pada Tanaman A steraceae di Bali 
I WAYAN SANDIKA YASA. et al. Kelimpahan Populasi dan Tingkat Parasitisasi Parasitoid...

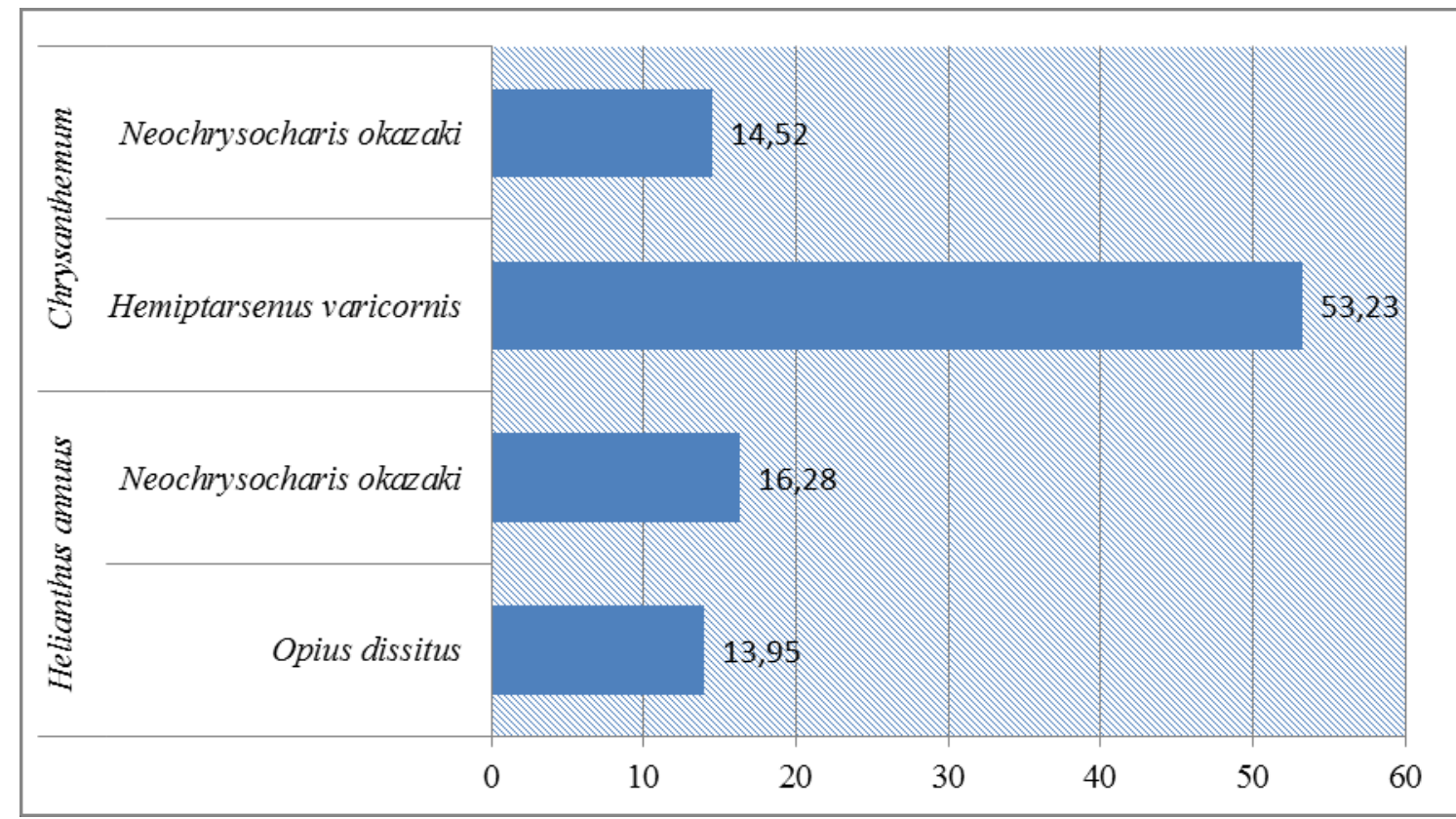

Gambar 3.Tingkat Parasitisasi Parasitoid (\%) yang Berasosiasi dengan Liriomyzatrifolii pada Tanaman A steraceae di Bali

Gambar 2 dan 3 menunjukkan nilai kelimpahan dan parasitisasi parasitoid yang berasosiasi dengan Liriomyzatrifolii pada tanaman A steraceae di Bali. Tingkat $p$ arasitisasi dan nisbah kelamin parasitoid merupakan indicator untuk menilai keunggul anparsitoid sebagai agen hayati (Supartha, 2002). Berdasarkan hasil pengamatan, nilai kelimpahan dan parasitisasi parasitoid yang berasosiasi dengan Liriomyzatrifolii paling tinggi muncul dari $H$. varicornis pada tanaman Krisan dengan nilai kelimpahan sebesar $78,57 \%$ dan tingkat parasitisasi sebesar 53,23 $\%$. Tingginya nilai kelimpahan dan parasitisasi parasitoid $H$. varicornis pada tanaman Krisan diakibatkan kondisi lingkungan dan ketersediaan inang yang cukup, halini sesuai dengan pendapat Thomson et. al. (2010) kondisi ekologi seperti cuaca, suhu, dan ketersediaan inang dapat memengaruhi aktivitas parasitoid.

Pada tanaman Gerbera tidak ditemukan parasitoid yang muncul, halini diduga karena aplikasi insektisida yang secara rutin dilakukan. Pernyataan ini didukung oleh Murphy \& LaSalle (1999) yang menyatakan bahwa insektisida juga sangat mengganggu agen pengendali biologis yang terjadi secar alami, terutama parasitoid, dan pernyataan tersebut dikuatkan lagi dari hasil penelitian Prijonoet al. (2002) bahwa aplikasi insektisida yang berlebihan menyebabkan kematian pada imago parasitoid. 


\section{SIMPULAN}

Berdasarkan hasil penelitian yang telah dilakukan terdapat tiga jenis parasitoid yang berasosiasi dengan Liriomyzatrifolii pada tanaman A steraceae di Bali yaitu

\section{Hemiptarsenusvaricornis,}

Neochrysocharisokazaki, dan Opiusdissitus. Dari ketiga jenis parasitoid tersebut $H$. varicornis merupakan parasitoid yang paling dominan dengan nilai kelimpahan 78,57\% dan tingkat parasitisasi sebesar 53,23\% pada tanaman Chrysanthemum.

\section{UPACAPAN TERIMAKASIH}

Penulis mengucapkan terima kasih kepada Prof. Dr. Ir. I Wayan Supartha, M.S. selaku Ketua Laboratorium Pengelolaan Terpadu Hama dan Penyakit Tumbuhan Fakultas Pertanian, Universitas Udayana karena telah memberikan segala fasilitas yang dibutuhkan untuk menyelesaikan penelitian ini.

\section{DAFTAR PUSTAKA}

Altieri, M. A. 1999. The ecological role of biodiversity in agroecosystems. J AgricEcosyst Environ 4: 19-31. Baliadi Y, Tengkano W. 2010. Leafminer fly, Liriomyza sp. (Diptera: Agromyzidae), new pest on soybean in Indonesia. JAgric Res Develop 29 (1): 1-9.

Cisneros, F. \&Mujica, N. (2000) Theleafminer fly in potato: plant reaction and natural enemies as natural mortality factors, In: International Potato Centre Program Report 199798. International Potato Center, Lima.

Cronquist, A. 1981. An Integrated System of Classification of Flowering Plants.Columbia University Press, New York.

Malipatil, M.,Ridland, P. 2008. Polyphagus Agromyzid Leafminer. Department of Agriculture, Fisheries, and Forestry, Australia.

Murphy, S. T., LaSalle, J. 1999. Balancing biological control strategies in the IPM of New World invasive Liriomyzaleafminers in field vegetable crops.Biocontrol News and Information 20: $91 \mathrm{~N}-104 \mathrm{~N}$.

Petcharat, J. 2002. Larval parasitoids of agromyzidleafminer genus in the southern thailand: species and their host plants. Songklanakarin J SciTechnol 24: 467-472.

Rauf, A., Shepard, B. M., Jhonson, M. W. 2000. Leafminer in vegetables, ornamental plants and weeds in indonesia: surveys of host crops, species composition and parasitoids. Intl J Pest Manag 48 (4).

Setiawati, W., Suprihatno, B. 2000.Utilities of biological agent on vegetables plant. Technical Meeting Utilities of Biological Agent, Cisarua Bogor, 2022 September 2000.

Syamsudin, H. 2008. Distribution of HemiptarsenusvaricornisGirault

(Hymenoptera: Eulopidae), Larval Parasitoid of Liriomyzaspp. (Diptera: Agromyzidae). Lembaga Pertanian Sehat, Jakarta.

Supartha, IW. 1998. Bionomics of Liriomyzahuidobrensis (Blanchard) (Diptera: Agromyzidae) on potato. Dissertation, Bogor University of Agriculture, Indonesia. $146 \mathrm{p}$.

Supartha, I W. 2002.Pengembangan hayati Liriomyzaspp. Pada berbagai tanaman 
I WAYAN SANDIKA YASA. et al. Kelimpahan Populasi dan Tingkat Parasitisasi Parasitoid...

sayuran di Bali. Makalah Utama

Seminar Pengembangan Pengendalian Hayati Pada Tanaman Sayuean di Bali.

Supartha, IW. 2003. Parasitoids fauna diversity of Liriomyzaspp. on vegetable crop in Bali and Lombok of Indonesia. 4th Congress of Indonesian Entomological Society and Symposium 2003.Cipayung Bogor (Indonesia) 3-7 March 2003.

Supartha, IW., Bagus IGN., Sudiarta, P. 2005. Population abundance of Liriomyzaspp. (Diptera: Agromyzidae) and parasitoids on highland vegetables crop. Agritrop 24 (2): 51-59.

Thompson, L. J., Macfadyen, S., Hoffmann, A. A. 2010.Predicting the effects of climate change on natural enemies of agricultural pests.Biol Cont. 52:296-306.

Ubaidillah R. 2003. Parasitoid wasps of Eulophinae (Hymenoptera: Eulophidae) in East Lesser Sunda, Indonesia. Treubia 33 (1): 43-70.

Wahyuni, S., Supartha IW., Ubaidillah, R., and Wijaya, I N. 2017. Parasitoid community structure of leaf miner Liriomyza spp. (Diptera: Agromyzidae) and the rate of parasitization on vegetable crops in Lesser Sunda Island, Indonesia. Biodiversitas. 18(2): 593-600. DOI: 10.13057/biodiv/d180221. 